\title{
Tumorigenicity Evaluation of Umbilical Cord Blood-derived Mesenchymal Stem Cells
}

\author{
Sang-Jin Park ${ }^{1, \dagger}$, Hyun-Jung Kim ${ }^{1, \dagger}$, Woojin Kim ${ }^{1}$, Ok-Sun Kim ${ }^{1}$, Sunyeong Lee ${ }^{1}$, Su-Yeon Han ${ }^{1}$, \\ Eun Ju Jeong ${ }^{1}$, Hyun-shin Park ${ }^{2}$, Hea-Won Kim² and Kyoung-Sik Moon' \\ ${ }^{1}$ Department of Toxicological Evaluation and Research, Korea Institute of Toxicology, Daejeon, Korea \\ ${ }^{2}$ Research Institute, Genexine Co., Seongnam, Korea
}

(Received November 24, 2015; Revised February 18, 2016; Accepted June 1, 2016)

\begin{abstract}
Mesenchymal stem cells (MSCs) have been identified in multiple types of tissue and exhibit characteristic self-renewal and multi-lineage differentiation abilities. However, the possibility of oncogenic transformation after transplantation is concerning. In this study, we investigated the tumorigenic potential of umbilical cord blood-derived MSCs (hUCB-MSCs) relative to MRC-5 and HeLa cells (negative and positive controls, respectively) both in vitro and in vivo. To evaluate tumorigenicity in vitro, anchorage-independent growth was assessed using the soft agar colony formation assay. hUCB-MSCs and MRC-5 cells formed few colonies, while HeLa cells formed a greater number of larger colonies, indicating that hUCBMSCs and MRC-5 cells do not have anchorage-independent proliferation potential. To detect tumorigenicity in vivo, hUCB-MSCs were implanted as a single subcutaneous injection into BALB/c-nu mice. No tumor formation was observed in mice transplanted with hUCB-MSCs or MRC-5 cells based on macroand microscopic examinations; however, all mice transplanted with HeLa cells developed tumors that stained positive for a human gene according to immunohistochemical analysis. In conclusion, hUCBMSCs do not exhibit tumorigenic potential based on in vitro and in vivo assays under our experimental conditions, providing further evidence of their safety for clinical applications.
\end{abstract}

Key words: Tumorigenicity, Mesenchymal stem cells, Immunohistochemistry, Soft agar assay

\section{INTRODUCTION}

Mesenchymal stem cells (MSCs) have been identified in multiple types of tissue including bone marrow, umbilical cord, and adipose (1). They came to prominence as a potential source of stem cells for cellular and genetic therapies due to their inherent abilities of self-renewal, proliferation, and functional multi-lineage differentiation (i.e., bone, cartilage, neurons, adipocytes, and cardiomyocytes). Clinical use of MSCs is emerging, providing valuable insight into

Correspondence to: Kyoung-Sik Moon, Department of Toxicological Evaluation and Research, Korea Institute of Toxicology, 141 Gaejeongro, Yuseong-gu, Daejeon 34114, Korea

E-mail : ksmoon@kitox.re.kr

${ }^{\dagger}$ Theses authors contributed equally to this study.

This is an Open-Access article distributed under the terms of the Creative Commons Attribution Non-Commercial License (http:// creativecommons.org/licenses/by-nc/3.0) which permits unrestricted non-commercial use, distribution, and reproduction in any medium, provided the original work is properly cited. regenerative medicine and tissue engineering (2-6).

However, therapeutic applications of MSCs are limited, owing to concerns that they could be prone to malignant transformation. It was reported that ex vivo expansion of mouse bone marrow MSCs induced transformation with subsequent generation of sarcomas after implantation in baboons (7). Furthermore, one study documented that bone marrow-derived cells, presumably MSCs, progressed from metaplasia and dysplasia to gastric epithelial cancer in mice with chronic mucosal injury (8).

Therefore, the tumorigenic potential of MSCs is a major concern in clinical applications, and regulatory guidelines recommend evaluating their tumorigenicity using immunocompromised animals to assess stem cell safety (9). To use MSCs safely in stem cell therapy in humans, it is important to determine whether human MSCs progress to malignant transformation. The purpose of this study was to investigate the potential malignant transformation of human umbilical cord blood-derived mesenchymal stem cells (hUCB-MSCs) using in vitro and in vivo tumorigenicity assays. 


\section{MATERIALS AND METHODS}

Cell lines and experimental animals. hUCB-MSCs were provided by Kang Stem Biotech (Seoul, Korea) and maintained as previously reported (10). Cells at passage 6 were used for all experiments (11). To compare the in vitro and in vivo tumorigenic potential of hUCB-MSCs, HeLa (human adenocarcinoma) and MRC-5 (human lung fibroblast) cell lines were used as positive and negative controls, respectively (American Type Culture Collection, VA, USA). HeLa and MRC-5 cells were cultured in Eagle's Minimum Essential Medium (EMEM, ATCC, VA, USA) supplemented with $10 \%$ fetal bovine serum (FBS, ATCC, VA, USA) in an incubator at $37^{\circ} \mathrm{C}$ with $5 \% \mathrm{CO}_{2}$.

To examine tumorigenicity in vivo, 4-week-old BALB/c$\mathrm{nu} / \mathrm{nu}$ female mice were purchased from Japan SLC Co. (Shizuoka, Japan). Mice were housed two per filter-top polycarbonate cage with aspen bedding at $23 \pm 3^{\circ} \mathrm{C}$ with a relative humidity of $50 \pm 10 \%$, air ventilation of $10 \sim 20$ times/ hr, and light intensity of 150 300 Lux under a 12-hr light/ dark cycle throughout the experimental period. The temperature and relative humidity of the room were maintained automatically, and ventilation frequency and light intensity were monitored periodically. Sterile pellet food (Labdiet \#5053, PMI Nutrition International, St. Louis, USA) and water were available ad libitum. This animal study was reviewed and assessed by the Institutional Animal Care and Use Committee (IACUC) of the Korea Institute of Toxicology (KIT).

In vitro tumorigenicity assay. To evaluate tumorigenicity in vitro, anchorage-independent growth was assessed with the soft agar colony formation assay using the 96-well plate. Briefly, the base agar layer was prepared from a $0.6 \%$ soft agar solution containing Dulbecco's Modified Eagle's Medium (DMEM) containing FBS in a 96-well plate. Then, $1 \times 10^{4}$ cells were suspended in DMEM containing FBS and $0.4 \%$ agar solution and plated onto the base layer. Plates were incubated at $37^{\circ} \mathrm{C}$ with $5 \% \mathrm{CO}_{2}$ for 7 days, after which colony formation was observed under a microscope.

In vivo tumorigenicity assay. Mice were divided randomly into four groups of six. Vehicle control (EMEM), hUCB-MSCs, MRC-5 cells, and HeLa cells $\left(1 \times 10^{7}\right.$ cells/ head) were inoculated subcutaneously once into the lateral trunk region. After inoculation, mice were observed for 13 weeks twice daily for clinical signs and twice weekly for the presence of tumors. Tumor dimension was assessed using a vernier caliper, and tumor size was estimated using the following equation: $1 / 2 \times$ minor axis ${ }^{2} \times$ major axis. Body weight was measured once weekly throughout the study period.

Thirteen weeks after inoculation, animals were fasted overnight and necropsied under deep isoflurane inhalation anesthesia. Blood samples were collected from the posterior vena cava of animals for hematologic analysis. Complete gross examinations were conducted on all animals. Organs including the liver, brain, spleen, heart, kidney, adrenal gland, and lung were collected and weighed. In addition, relative organ weights were calculated as the ratio of organ weight-to-fasted body weight before necropsy.

Routine hematological examinations were conducted using blood with EDTA-2K, an anticoagulant, on a hematological auto-analyzer (ADVIA120 Hematology System, Bayer, USA) to assess: white blood cell (WBC) count, red blood cell (RBC) count, hemoglobin (HGB) concentration, hematocrit (HCT), mean corpuscular volume (MCV), mean corpuscular hemoglobin $(\mathrm{MCH})$, mean corpuscular hemoglobin concentration (MCHC), platelets (PLT), differential leukocyte count (neutrophil (NEU), lymphocyte (LYM), monocyte (MON), eosinophil (EOS), basophil and large unstained cell (BAS) and reticulocyte count (RET).

The organs collected for histopathology including the kidney, liver, spleen, heart, brain, lung, adrenal gland, mandibular lymph node, stomach, mesenteric lymph node, pancreas, thoracic cavity, skin, and injection site were fixed in $10 \%$ neutral-buffered formalin. Fixed organs from all animals were embedded in paraffin, sectioned, stained with hematoxylin and eosin (H\&E), and examined under a microscope.

Human gene expression at the injection site. To determine whether inoculated hUCB-MSCs persisted at the injection site and whether tumor formation in HeLa celltreated mice originated from inoculated cells, immunohistochemistry (IHC) was performed on injection site tissues or observed tumor tissues of animals from each group using an automated staining system (DISCOVERY XT, Ventana, Tucson, USA). Heat-induced epitope retrieval was applied using citrate-based buffer ( $\mathrm{pH}$ 6.0). Sections were incubated with an anti-human mitochondria mouse monoclonal antibody ( $1: 1000$, ab92824, Abcam, Cambridge, UK) for $2 \mathrm{hr}$. For detection, diaminobenzidine chromogen was used and counterstained with hematoxylin.

Statistical analysis. The data were examined for variance homogeneity using Bartlett's test. When Bartlett's test indicated no significant deviations from variance homogeneity, a one-way analysis of variance (ANOVA) was performed at $\alpha=0.05$. When significance was noted, Dunnett's test for multiple comparisons was conducted to determine which pairs were significantly different. When pairs of group homogeneity were observed, the non-parametric Kruskal-Wallis comparison test was conducted. When a significant difference was observed in the Kruskal-Wallis test, Dunn's Rank Sum test was conducted to determine the specific pairs of group comparison. Statistical analyses were performed using the PATH/TOX System (Version 4.2.2, 
hUCB-MSCs

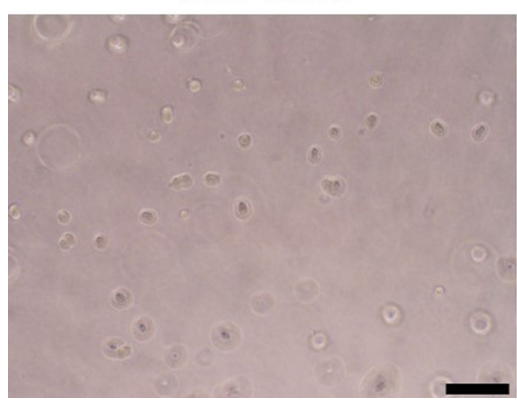

MRC-5

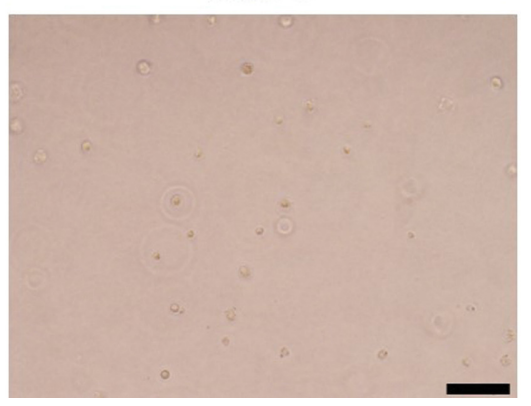

HeLa

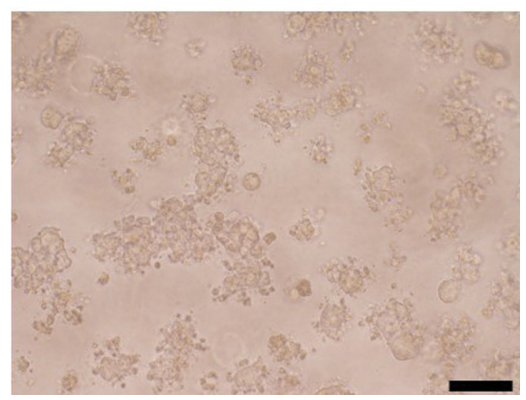

Fig. 1. Representative images of colonies in the soft agar assay for hUCB-MSCs, MRC-5 cells, and HeLa cells. HeLa cells, but not MRC-5 cells or hUCB-MSCs, showed anchorage-independent cell growth in soft agar. Bar $=40 \mu \mathrm{m}$.

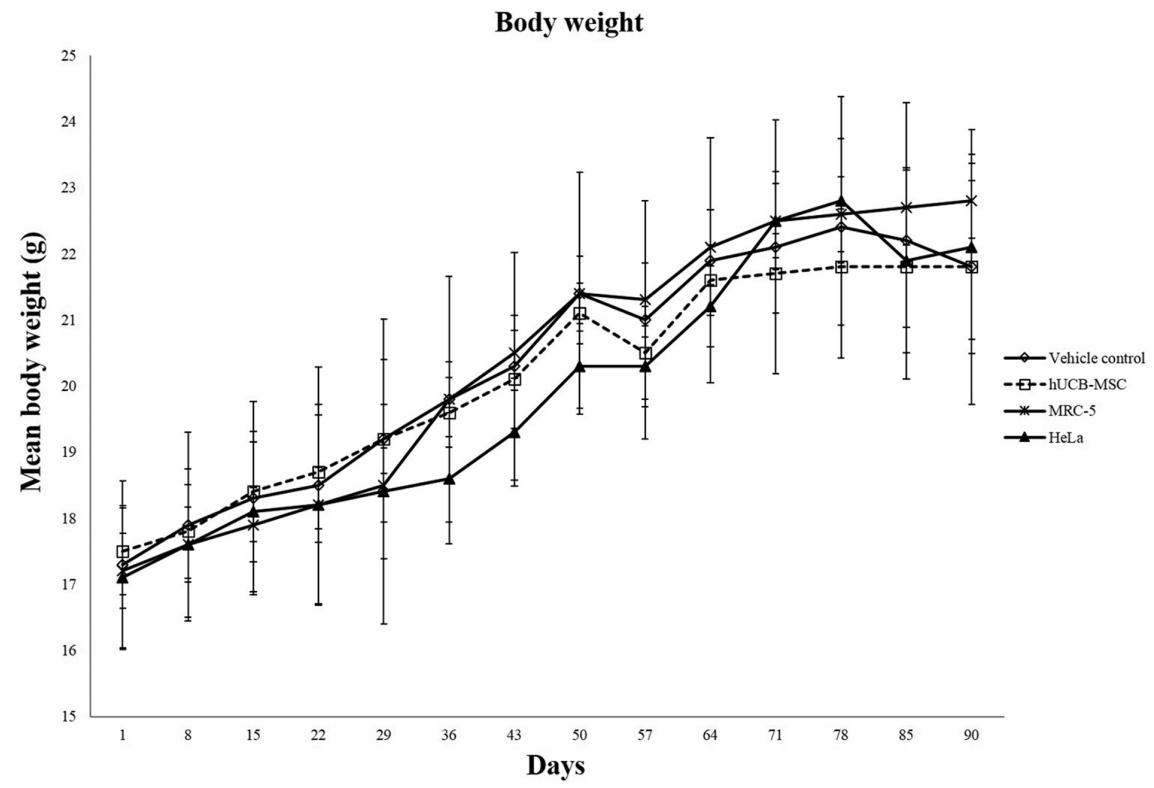

Fig. 2. Body weight changes following subcutaneous transplantation of hUCB-MSCs, MRC-5 cells, and HeLa cells. No significant body weight changes were observed in BALB/c Slc-nu/nu mice after transplantation of hUCB-MSCs, MRC-5, or HeLa cells. Values are expressed as the mean \pm SD and significant difference compared to the control $(p<0.05)$.

Xybion Co., Cedar Knolls, USA). Significance was set as $p<0.05$.

\section{RESULTS}

In vitro tumorigenicity assay. To compare colony formation of hUCB-MSCs with HeLa and MRC-5 cells, we performed the soft agar colony assay using $1 \times 10^{4}$ cells/ well in a 96-well plate. hUCB-MSCs showed a notably lower ability to form colonies than HeLa cells (positive control). The vehicle control and MRC-5 groups did not form colonies (Fig. 1).

In vivo tumorigenicity assay. No significant body weight changes were observed in any of the groups during the experimental period (Fig. 2). Upon clinical observation,

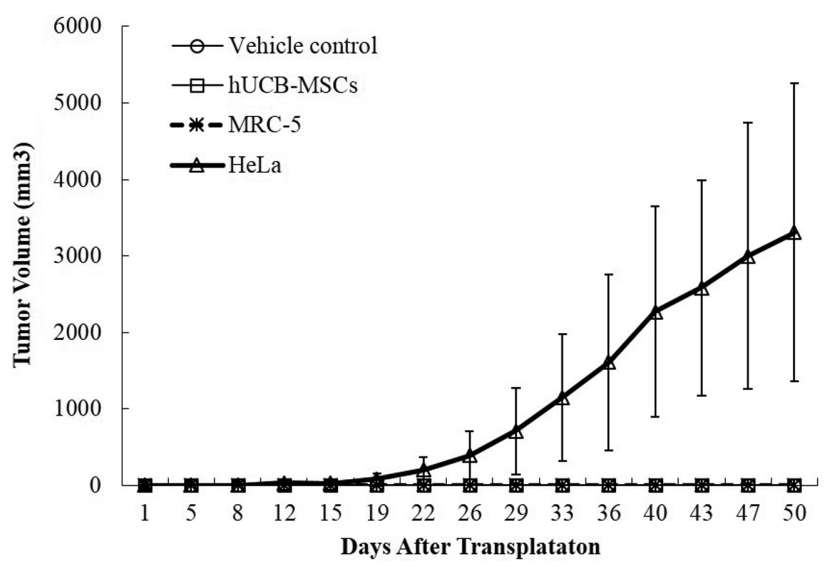

Fig. 3. Tumor volume changes in mice transplanted with vehicle control, hUCB-MSCs, MRC-5 cells, and HeLa cells. Tumor volume was measured twice weekly. 
Table 1. Hematology after transplanting hUCB-MSCs, MRC-5 cells, and HeLa cells in BALB/c-nu mice

\begin{tabular}{lcccc}
\hline \hline & & & Group \\
\cline { 2 - 5 } Parameter & Control & hUCB-MSC & MRC-5 & HeLa \\
\hline WBC $\left(\times 10^{9} / \mathrm{L}\right)$ & $3.45 \pm 2.443$ & $4.56 \pm 1.722$ & $3.36 \pm 1.260$ & $61.80 \pm 166.819$ \\
RBC $\left(\times 10^{12} / \mathrm{L}\right)$ & $10.62 \pm 0.584$ & $9.90 \pm 0.855^{*}$ & $9.37 \pm 2.030$ & $9.91 \pm 1.237$ \\
HGB $(\mathrm{g} / \mathrm{dL})$ & $1.59 \pm 0.98$ & $14.0 \pm 1.46^{* *}$ & $14.1 \pm 3.10$ & $13.7 \pm 1.78^{* *}$ \\
HCT $(\%)$ & $51.5 \pm 2.72$ & $49.0 \pm 4.55$ & $46.5 \pm 10.10$ & $46.0 \pm 5.33^{* *}$ \\
MCV (fL) & $48.6 \pm 1.68$ & $49.5 \pm 0.79$ & $49.5 \pm 1.08$ & $46.6 \pm 3.41$ \\
MCH (pg) & $14.9 \pm 0.46$ & $14.2 \pm 0.93$ & $15.1 \pm 0.36$ & $13.9 \pm 1.27^{*}$ \\
MCHC (g/dL) & $30.7 \pm 0.68$ & $28.6 \pm 2.23^{* *}$ & $30.4 \pm 0.65$ & $29.8 \pm 0.71^{* *}$ \\
PLT ( $10 \% / \mathrm{L})$ & $1256 \pm 205.0$ & $1214 \pm 519.4$ & $1170 \pm 208.4$ & $1519 \pm 426.1 *$ \\
RET (\%) & $512.6 \pm 384.77$ & $477.7 \pm 205.50$ & $347.4 \pm 99.68$ & $561.8 \pm 179.57$ \\
NEU (\%) & $1.57 \pm 0.835$ & $2.29 \pm 0.709$ & $1.77 \pm 0.560$ & $56.81 \pm 154.338^{*}$ \\
LYM (\%) & $1.73 \pm 1.641$ & $2.01 \pm 1.016$ & $1.42 \pm 0.786$ & $1.26 \pm 1.843$ \\
MON (\%) & $0.04 \pm 0.030$ & $0.05 \pm 0.028$ & $0.04 \pm 0.018$ & $0.81 \pm 2.413$ \\
EOS (\%) & $0.06 \pm 0.035$ & $0.10 \pm 0.072$ & $0.09 \pm 0.105$ & $2.28 \pm 7.024$ \\
BAS (\%) & $0.01 \pm 0.008$ & $0.02 \pm 0.015$ & $0.01 \pm 0.013$ & $1.19 \pm 3.664$ \\
\hline
\end{tabular}

Values are expressed as the mean \pm SD.

$*$, Significant difference compared to the control $(p<0.05)$.

**, Significant difference compared to the control $(p<0.01)$.

Table 2. Macroscopic findings with abnormal lesions after transplanting hUCB-MSCs, MRC-5 cells, and HeLa cells in BALB/c-nu mice

\begin{tabular}{lcccc}
\hline \hline Parameter & \multicolumn{3}{c}{ Group } \\
\cline { 2 - 5 } & Control & hUCB-MSC & MRC-5 & HeLa \\
\hline No. of animals & 6 & 6 & 6 & 6 \\
Mass & & & 0 & 6 \\
$\quad$ Mass in injection site & 0 & 0 & 0 & 1 \\
$\quad$ Mass in thoracic cavity & 0 & 0 & 0 & 3 \\
Abnormal lesion & 0 & 0 & & \\
$\quad$ Splenomegaly & & & & \\
\end{tabular}

mice treated with hUCB-MSCs or MRC-5 cells had no clinical signs, but HeLa cell-treated mice exhibited swollen skin $(6 / 6)$, a palpable mass (6/6), and hard skin (1/6) with an increased tumor volume during the experimental period (Fig. 3). Upon hematologic evaluation, there were no meaningful differences between control and hUCB-MSC-treated

Table 3. Microscopic findings after transplanting hUCB-MSCs, MRC-5 cells, and HeLa cells in BALB/c-nu mice

\begin{tabular}{|c|c|c|c|c|}
\hline \multirow{2}{*}{ Parameter } & \multicolumn{4}{|c|}{ Group } \\
\hline & Control & hUCB-MSC & MRC-5 & HeLa \\
\hline No. of animals & 6 & 6 & 6 & 6 \\
\hline \multicolumn{5}{|l|}{ Kidneys } \\
\hline Inflammatory cell infiltration & 0 & 0 & 3 & 0 \\
\hline \multicolumn{5}{|l|}{ Liver } \\
\hline Inflammatory cell infiltration & 1 & 0 & 1 & 0 \\
\hline Extramedullary hemopoiesis & 0 & 0 & 0 & 1 \\
\hline \multicolumn{5}{|l|}{ Spleen } \\
\hline Extramedullary hemopoiesis & 0 & 0 & 0 & 5 \\
\hline \multicolumn{5}{|l|}{ Heart } \\
\hline Cardiomyopathy & 1 & 1 & 0 & 0 \\
\hline Inflammatory cell infiltration & 0 & 0 & 1 & 0 \\
\hline \multicolumn{5}{|l|}{ Lung } \\
\hline Alveolitis & 0 & 1 & 0 & 0 \\
\hline Hemorrhage & 0 & 0 & 0 & 2 \\
\hline
\end{tabular}


Table 3. Continued

\begin{tabular}{|c|c|c|c|c|}
\hline \multirow{2}{*}{ Parameter } & \multicolumn{4}{|c|}{ Group } \\
\hline & Control & hUCB-MSC & MRC-5 & $\mathrm{HeLa}$ \\
\hline \multicolumn{5}{|l|}{ Adrenal glands } \\
\hline Subcapsular cell hyperplasia & 5 & 4 & 4 & 4 \\
\hline Corticomedullary vacuolation & 5 & 4 & 4 & 2 \\
\hline \multicolumn{5}{|l|}{ Mandibular lymph node } \\
\hline Extramedullary hemopoiesis & 3 & 3 & 2 & 3 \\
\hline \multicolumn{5}{|l|}{ Stomach } \\
\hline Erosion/ulcer & 0 & 1 & 1 & 2 \\
\hline \multicolumn{5}{|l|}{ Mesenteric lymph node } \\
\hline Extramedullary hemopoiesis & 0 & 0 & 0 & 2 \\
\hline Inflammtory cell infiltration, granulocytes & 0 & 1 & 0 & 0 \\
\hline Giant cell infiltration & 0 & 1 & 0 & 0 \\
\hline \multicolumn{5}{|l|}{ Injection site } \\
\hline Tumor mass/HeLa cells, subcutaneous & 0 & 0 & 0 & 6 \\
\hline \multicolumn{5}{|l|}{ Thoracic cavity } \\
\hline Tumor mass & 0 & 0 & 0 & 1 \\
\hline \multicolumn{5}{|l|}{ Skin } \\
\hline Keratin cyst & 0 & 0 & 0 & 1 \\
\hline
\end{tabular}
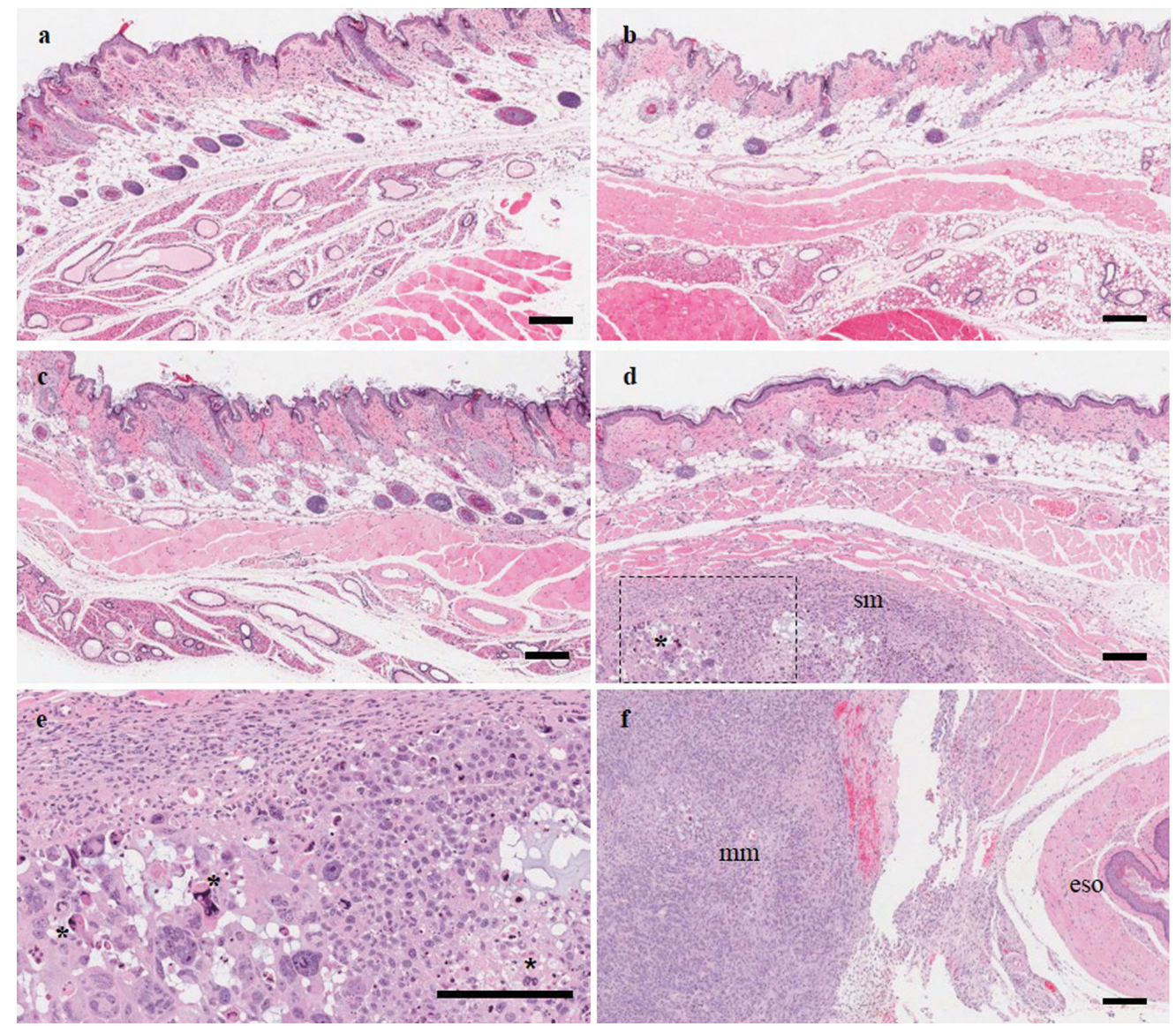

Fig. 4. Histopathology of injection sites and formation of subcutaneous and metastatic cell masses. No cell mass formation was observed in the (a) control, (b) hUCB-MSCs, or (c) MRC-5 cell injection sites. However, the (d) HeLa cell injection site showed a subcutaneous mass (sm). Mitotic figures (asterisks) were observed in the dotted square. These were confirmed in the magnified picture (e), which also showed rounded or pleomorphic cells with hyperchromatic nuclei. (f) A metastatic cell mass (mm) in the thoracic cavity had the same cellular components as the subcutaneous mass. Esophagus (eso). Bar $=200 \mu \mathrm{m}$. 
groups (Table 1). There were no treatment-related findings according to macroscopic examination in the vehicle control, MRC-5-, or hUCB-MSC-treated mice (Table 2). Microscopic examination revealed no tumors in the vehicle control, MRC-5, or hUCB-MSC-treated groups. However, all mice inoculated with HeLa cells developed tumors at the injection site, with one case presenting metastasis to the thoracic cavity (Table 2, Table 3). The tumor lesions presented mitotic figures, necrosis, and rounded or pleomorphic cells with hyperchromatic nuclei (Fig. 4). In addition, extramedullary hemopoiesis with splenomegaly was observed in HeLa cell-treated mice (Table 3 ).

Human gene detection at the injection site. Tumor formation of inoculated human cells can be detected by immunostaining the injection site tissue sections of animals with a human-specific antibody (12). No human mitochondrial antigen expression was observed at the injection site in the vehicle control, hUCB-MSCs, or MRC-5 cell-treated groups, while the HeLa cell-treated group showed high human mitochondrial antigen expression in tumors at the injection site (Fig. 5).

\section{DISCUSSION}

Mesenchymal stem cells are a promising tool for cell therapies because they are easily sourced from various tissues and have properties of tissue revascularization and repair. Previous non-clinical and clinical studies have reported on the therapeutic value of MSCs (13-16). However, some studies have reported adverse effects of MSCs, including tumor growth and mutation into tumor cells (17-20). Moreover, one patient with the neurodegenerative hereditary disorder ataxia telangiectasia treated with human fetal neural stem cells by intracerebellar and intrathecal injection developed a multifocal brain tumor of non-host origin. This suggested that the tumor was derived from the transplanted neural stem cells (21). These reports indicate the importance of
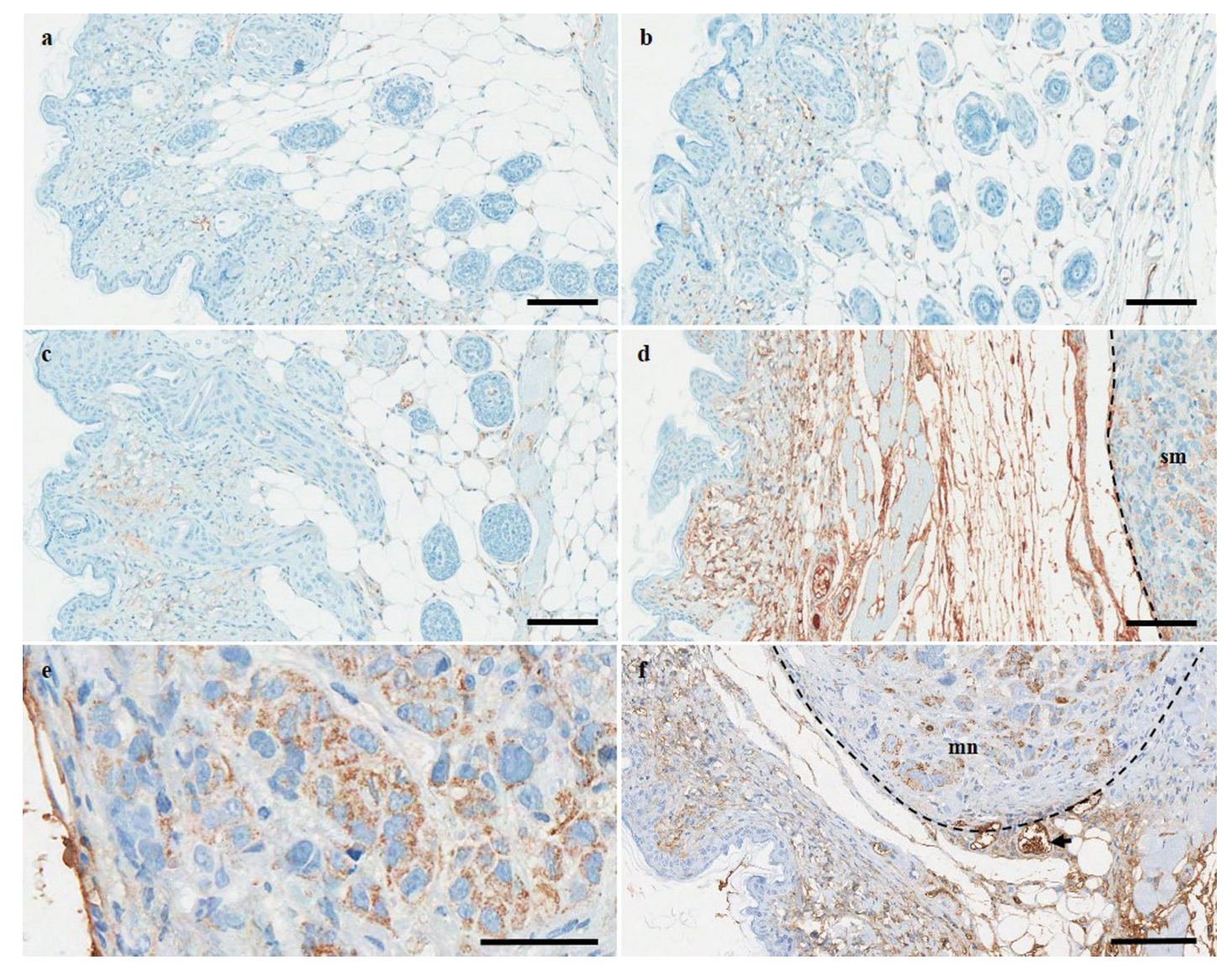

Fig. 5. Immunohistochemical analysis of a human mitochondrial marker at the injection site. Immunohistochemical analysis of a human mitochondrial antigen revealed no expression in the (a) control, (b) hUCB-MSCs, or (c) MRC-5 cell groups. The HeLa cell group showed a tumor mass (sm, right side of the dotted line) in the (d) subcutaneous and metastatic tumor nodules (mn, upper side of the dotted line) in the (f) dermis. (e) The human mitochondrial antigen was expressed well in the cytoplasm of tumor cells. HeLa celltreated mice showed strong background staining because the tumor mass exhibits dramatic (d) angiogenesis and hemopoiesis. $\operatorname{Bar}=50 \mu \mathrm{m}$. 
investigating the tumorigenicity of MSCs for their use in clinical applications.

In this study, we evaluated the tumorigenicity of hUCBMSCs in vitro with the soft agar colony formation assay, which is used to measure cell anchorage-independent proliferation potential. Anchorage-independent growth is a hallmark of transformation and the most accurate in vitro indication of tumorigenicity (22). In this study, hUCB-MSCs formed few colonies, while HeLa cells formed a greater number of larger colonies, indicating that hUCB-MSCs do not possess anchorage-independent proliferation potential. The less tumorigenic effect of hUCB-MSCs in vitro than HeLa cells corresponds with recent results of other MSCs $(23,24)$.

With increasing passages of stem cell lines, there is increased potential for chromosomal aberrations, a hallmark of tumor formation (9). The hUCB-MSCs in this study were used at passage 6 and had no evidence of tumorigenicity, suggesting that hUCB-MSCs may be chromosomally stable at least up to passage 6 under our culture conditions, as they were not prone to malignant transformation. In agreement with our results, Ra et al. (25) reported that chromosomal abnormalities were not observed in human adipose tissue-derived MSCs (hAdMSCs) from passages 4 12.

In our 13-week tumorigenicity study in which hUCBMSCs were transplanted into female BALB/c-nu/nu mice, there were no tumor formation-related findings in body weight, clinical signs, gross findings, organ weight, hematology, or macro- and microscopic examination. However, all HeLa cell-treated mice developed tumors. These findings correlate with the clinical observations and macro- and microscopic examinations. Our results obtained from in vivo and in vitro tumorigenicity studies consistently demonstrated that hUCB-MSCs did not induce tumor formation. These data correspond with a previous study, which reported no tumorigenicity of hAdMSCs in immunocompromised animals (25).

According to immunohistochemical analysis, no human mitochondrial antigen expression was observed in the vehicle control and hUCB-MSC-treated groups, indicating a lack of human cell persistence. However, the tumors observed in the HeLa cell-treated mice likely originated from the inoculated HeLa cells based on the detection of human mitochondrial antigen expression.

In this study, tumorigenicity was studied after 13 weeks. However, when allogeneic bone marrow-derived MSCs were injected intravenously into baboons, high amounts of MSC DNA were detected in the kidney, lung, thymus, liver, gastrointestinal, and skin tissues until 19 months post-treatment. Moreover, hAdMSCs survived in mice with severe combined immunodeficiency for 17 months after subcutaneous injection and differentiated into fibroblasts of the subdermic connective tissue and mature adipocytes of fat tissue at the injection site (26). These reports suggest that the duration of this study might have been insufficient. Therefore, a long-term study is required to validate these findings.

In conclusion, our data show that hUCB-MSCs have no in vitro or in vivo tumorigenic potential under our study conditions, providing further evidence of the safety of MSCs for clinical applications. However, further studies are required to address the long-term tumorigenicity of human MSCs in animals.

\section{REFERENCES}

1. Lee, O.K., Kuo, T.K., Chen, W.M., Lee, K.D., Hsieh, S.L. and Chen. T.H. (2004) Isolation of multipotent mesenchymal stem cells from umbilical cord blood. Blood, 103, 1669-1675.

2. Bartholomew, A., Sturgeon, C., Siatskas, M., Ferrer, K., McIntosh, K., Patil, S., Hardy, W., Devine, S., Ucker, D., Deans, R., Moseley, A. and Hoffman, R. (2002) Mesenchymal stem cells suppress lymphocyte proliferation in vitro and prolong skin graft survival in vivo. Exp. Hematol., 30, 42-48.

3. Stamm, C., Westphal, B., Kleine, H.D., Petzsch, M., Kittner, C., Klinge, H., Schümichen, C., Nienaber, C.A., Freund, M. and Steinhoff, G. (2003) Autologous bone-marrow stem-cell transplantation for myocardial regeneration. Lancet, 361, 4546.

4. Barry, F.P. and Murphy, J.M. (2004) Mesenchymal stem cells: clinical applications and biological characterization. Int. J. Biochem. Cell Biol., 36, 568-584.

5. Xu, W., Zhang, X., Qian, H., Zhu, W., Sun, X., Hu, J., Zhou, H. and Chen, Y. (2004) Mesenchymal stem cells from adult human bone marrow differentiate into a cardiomyocyte phenotype in vitro. Exp. Biol. Med. (Maywood), 229, 623-631.

6. Kassem, M. and Abdallah, B.M. (2008) Human bone-marrow-derived mesenchymal stem cells: biological characteristics and potential role in therapy of degenerative diseases. Cell Tissue Res., 331, 157-163.

7. Devine, S.M., Cobbs, C., Jennings, M., Bartholomew, A. and Hoffman, R. (2003) Mesenchymal stem cells distribute to a wide range of tissues following systemic infusion into nonhuman primates. Blood, 101, 2999-3001.

8. Houghton, J., Stoicov, C., Nomura, S., Rogers, A.B., Carlson, J., Li, H., Cai, X., Fox, J.G., Goldenring, J.R. and Wang, T.C. (2004) Gastric cancer originating from bone marrow-derived cells. Science, 306, 1568-1571.

9. Goldring, C.E., Duffy, P.A., Benvenisty, N., Andrews, P.W., Ben-David, U., Eakins, R., French, N., Hanley, N.A., Kelly, L., Kitteringham, N.R., Kurth, J., Ladenheim, D., Laverty, H., McBlane, J., Narayanan, G., Patel, S., Reinhardt, J., Rossi, A., Sharpe, M. and Park, B.K. (2011) Assessing the safety of stem cell therapeutics. Cell Stem Cell, 8, 618-628.

10. Yu, K.R., Lee, J.Y., Kim, H.S., Hong, I.S., Choi, S.W., Seo, Y., Kang, I., Kim, J.J., Lee, B.C., Lee, S., Kurtz, A., Seo, K.W. and Kang, K.S. (2014) A p38 MAPK-mediated alteration of COX-2/PGE2 regulates immunomodulatory properties in human mesenchymal stem cell aging. PLoS ONE, 9, e102426.

11. Kim, H.S., Shin, T.H., Lee, B.C., Yu, K.R., Seo, Y., Lee, S., Seo, M.S., Hong, I.S., Choi, S.W., Seo, K.W., Nunez, G., Park, J.H. and Kang, K.S. (2013) Human umbilical cord blood mes- 
enchymal stem cells reduce colitis in mice by activating NOD2 signaling to COX2. Gastroenterology, 145, 1392-1403.

12. Kawamata, S., Kanemura, H., Sakai, N., Takahashi, M. and Go, M.J. (2015) Design of a tumorigenicity test for induced pluripotent stem cell (iPSC)-derived cell products. J. Clin. Med., 4, 159-171.

13. Chuah, M.K., Damme, A.V., Zwinnen, H., Goovaerts, I., Vanslembrouck, V., Collen, D. and Vandendriessche, T. (2000) Long-term persistence of human bone marrow stromal cells transduced with factor VIII-retroviral vectors and transient production of therapeutic levels of human factor VIII in nonmyeloablated immunodeficient mice. Hum. Gene Ther., 11, 729-738.

14. Campagnoli, C., Bellantuono, I., Kumar, S., Fairbairn, L.J., Roberts, I. and Fisk, N.M. (2002) High transduction efficiency of circulating first trimester fetal mesenchymal stem cells: potential targets for in utero ex vivo gene therapy. BJOG, 109, 952-954.

15. Fouillard, L., Bensidhoum, M., Bories, D., Bonte, H., Lopez, M., Moseley, A.M., Smith, A., Lesage, S., Beaujean, F., Thierry, D., Gourmelon, P., Najman, A. and Gorin, N.C. (2003) Engraftment of allogeneic mesenchymal stem cells in the bone marrow of a patient with severe idiopathic aplastic anemia improves stroma. Leukemia, 17, 474-476.

16. Amado, L.C., Saliaris, A.P., Schulei, K.H., Marcus, S.J., Xie, J.S., Cattaneo, S., Durand, D.J., Fitton, T., Kuang, J.Q., Stewart, G., Lehrke, S., Baumgartner, W.W., Bradley, J.M., Heldman, A.W. and Hare, J.M. (2005) Cardiac repair with intramyocardial injection of allogeneic mesenchymal stem cells after myocardial infarction. Proc. Natl. Acad. Sci. U.S.A., 102, 11474-11479.

17. Djouad, F., Plence, P., Bony, C., Tropel, P., Apparailly, F., Sany, J., Noël, D. and Jorgensen, C. (2003) Immunosuppressive effect of mesenchymal stem cells favors tumor growth in allogeneic animals. Blood, 102, 3837-3844.

18. Sato, T., Sakai, T., Noguchi, Y., Takita, M., Hirakawa, S. and Ito, A. (2004) Tumor-stromal cell contact promotes invasion of human uterine cervical carcinoma cells by augmenting the expression and activation of stromal matrix metalloprotein- ases. Gynecol. Oncol., 92, 47-56.

19. Zhu, W., Xu, W., Jiang, R., Qian, H., Chen, M., Hu, J., Cao, W., Han, C. and Chen, Y. (2006) Mesenchymal stem cells derived from bone marrow favor tumor cell growth in vivo. Exp. Mol. Pathol., 80, 267-274.

20. Tolar, J., Nauta, A.J., Osborn, M.J., Panoskaltsis Mortari, A., McElmurry, R.T., Bell, S., Xia, L., Zhou, N., Riddle, M., Schroeder, T.M., Westendorf, J.J., McIvor, R.S., Hogendoorn, P.C., Szuhai, K., Oseth, L., Hirsch, B., Yant, S.R., Kay, M.A., Peister, A., Prockop, D.J., Fibbe, W.E. and Blazar, B.R. (2007) Sarcoma derived from cultured mesenchymal stem cells. Stem Cells, 25, 371-379.

21. Amariglio, N., Hirshberg, A., Scheithauer, B.W., Cohen, Y., Loewenthal, R., Trakhtenbrot, L., Paz, N., Koren-Michowitz, M., Waldman, D., Leider-Trejo, L., Toren, A., Constantini, S. and Rechavi, G. (2009) Donor-derived brain tumor following neural stem cell transplantation in an ataxia telangiectasia patient. PLoS Med., 6, e1000029.

22. Shin, S.I., Freedman, V.H., Risser, R. and Pollack, R. (1975) Tumorigenicity of virus-transformed cells in nude mice is correlated specifically with anchorage independent growth in vitro. Proc. Natl. Acad. Sci. U.S.A., 72, 4435-4439.

23. Sabapathy, V., Ravi, V., Srivastava, V., Srivastava, A. and Kumar, S. (2012) Long-term cultured human term placentaderived mesenchymal stem cells of maternal origin displays plasticity. Stem Cells Int., 2012, 174328.

24. Sabapathy, V., Sundaram, B., V.M.S., Mankuzhy, P. and Kumar, S. (2014) Human Wharton's Jelly mesenchymal stem cells plasticity augments scar-free skin wound healing with hair growth. PLoS ONE, 9, e93726.

25. Ra, J.C., Shin, I.S., Kim, S.H., Kang, S.K., Kang, B.C., Lee, H.Y., Kim, Y.J., Jo, J.Y., Yoon, E.J., Choi, H.J. and Kwon, E. (2011) Safety of intravenous infusion of human adipose tissue-derived mesenchymal stem cells in animals and humans. Stem Cells Dev., 20, 1297-1308.

26. Lopez-Iglesias, P., Blazquez-Martinez, A., Fernandez-Delgado, J., Regadera, J., Nistal, M. and Miguel, M.P. (2011) Short and long term fate of human AMSC subcutaneously injected in mice. World J. Stem Cells, 3, 53-62. 